\title{
Hydrogen content in chondrules of CM Chondrites: Influence of aqueous alteration or preaccretional heritage?
}

\author{
SAMANTHA AZEVEDO-VANNSON ${ }^{1}$, LAURENT \\ REMUSAT $^{2}$, LAURETTE PIANI ${ }^{3}$, SYLVAIN PONT ${ }^{4}$ AND \\ MATHIEU ROSKOSZ ${ }^{5}$ \\ ${ }^{1}$ IMPMC/CNRS HYDROMA \\ ${ }^{2} \mathrm{CNRS}$ - MNHN \\ ${ }^{3} \mathrm{CRPG}, \mathrm{CNRS}$-Lorraine Université \\ ${ }^{4}$ IMPMC, MNHN \\ ${ }^{5}$ Sorbonne Universités-IMPMC-MNHN-UMR-CNRS \\ Presenting Author: laurent.remusat@mnhn.fr
}

Carbonaceous chondrites have witnessed the early ages of the solar system. They are rich in volatiles including hydrogen, and they may have contributed to the volatile budget of Earth [1]. In this contribution, we have investigated the $\mathrm{H}$ content and $\mathrm{D} / \mathrm{H}$ isotope composition of the emblematic components of these meteorites: chondrules. Two main types of chondrules co-exist in carbonaceous chondrites [2], type I (FeO-poor) and type II (FeOrich), which were formed in a reducing and more oxidizing environment, respectively. We aim at constraining the origin of hydrogen contained in $\mathrm{CM}$ chondrules by disentangling the influence of aqueous alteration on the $\mathrm{CM}$ parent body and preaccretion intake. As the $\mathrm{D} / \mathrm{H}$ ratio exhibits a broad gradient throughout the solar system, from low values of the molecular $\mathrm{H}_{2}$ close to the central star [3] to D-rich rich water ice [4] outwards, assessing the $\mathrm{D} / \mathrm{H}$ ratio of $\mathrm{H}$ trapped in chondrules should shed light on their origin. Olivine in chondrules of three carbonaceous chondrites showing different alteration degrees were investigated by both NanoSIMS and SIMS IMS 1280: Paris (CM2.7 to 2.9), Aguas Zarcas (CM2) and Mukundpura (CM1/2). We determine $0.33<\left[\mathrm{H}_{2} \mathrm{O}\right]<0.87 \mathrm{wt} \%$ with $108 \times 10^{-6}<\mathrm{D} / \mathrm{H}<157 \times 10^{-6}$ in Paris, $0.15<\left[\mathrm{H}_{2} \mathrm{O}\right]<1.18 \mathrm{wt} \%$ with $74 \times 10^{-6}<\mathrm{D} / \mathrm{H}<150 \times 10^{-6}$ in Aguas Zarcas and $0.29<\left[\mathrm{H}_{2} \mathrm{O}\right]<0.82 \mathrm{wt} \%$ with $96 \times 10^{-6}<\mathrm{D} / \mathrm{H}$ $<160 \times 10^{-6}$ in Mukundpura. Moreover, Aguas Zarcas and Mukundpura exhibit a correlation between $\left[\mathrm{H}_{2} \mathrm{O}\right]$, [Fe] and D/H ratio: Fe-poor olivines constitute a water-poor D-rich endmember, while Fe-rich olivines contain more water with lower $\mathrm{D} / \mathrm{H}$. The correlations could be related to preaccretional incorporation of $\mathrm{H}$ followed by hydration and oxidation on the parent body, or to the evolution of chondrule precursors in the gas phase before the formation of parent bodies. These hypotheses will be discussed in the light of petrographic observation for each type of chondrules in the three studied CM chondrites.

[1] Vacher et al. (2020) Geochimica Cosmochimica Acta 281, 53-66

[2] Connolly and Jones (2016) J. Geophys. Res. Planets 121, 1885-1889

[3] Mahaffy, P.R. et al. (1998) Space Science Reviews 84, 251263

[4] Cleeves, I. et al. (2014) Science 345, 1590-1593 